Brendan C. O'Kelly', Ph.D. and Patrick J. Naughton ${ }^{2}$, Ph.D.

\title{
Engineering properties of wet-pluviated hollow cylindrical specimens
}

\begin{abstract}
A hollow cylinder apparatus was used to study some engineering properties of hollow cylindrical sand specimens prepared using the wet-pluviation technique. The refined specimen preparation method displayed good repeatability. Wet pluviation produced inherently cross-anisotropic specimens, with the level of initial anisotropy reducing with decreasing initial void ratio. The variation in the initial void ratio of the sand specimens was related to the volume of the specimens. The stress-strain responses under isotropic consolidation were not significantly affected by the small variations in the initial void ratios that occurred for a target initial specimen volume. The levels of membrane penetration recorded for the different specimens was independent of the applied cell confining pressure, and the amount of membrane penetration compared well with other experimental studies.
\end{abstract}

KEYWORDS: specimen preparation, wet pluviation, sand, hollow cylinder apparatus

\section{Introduction}

The sedimentation process and hence the inherent fabric of many natural sand deposits are reproduced in laboratory specimens prepared using the wet-pluviation technique. Wet pluviation alone produces specimens of very loose to loose relative densities. Specimen densification is achieved by tapping or vibrating the specimen mould to apply a set compaction energy or achieve a target void ratio, often aided by a temporary surcharge load placed on top of the specimen. Densification reduces the level of inherent anisotropy of the test specimen. The constitutive behavior of natural sand deposits can be studied by conducting laboratory tests on specimens prepared in this manner. The use of the hollow cylinder apparatus to study the constitutive responses of soil deposits under the generalized stress conditions encountered in practice is increasing. An important starting point for these studies is the requirement to consistently reproduce identical test specimens to allow more direct comparisons of the experimental results. More elaborate specimen preparation apparatus, which require both inner and outer specimen moulds, are necessary to form the hollow cylindrical sand specimens. Existing apparatus that employed the wet-pluviation technique included those reported by Ishihara and Yasuda (1975), Porovic (1995) and Vaid et al. (1990). Specimen boundary effects are also greater for hollow cylindrical specimens than for solid cylindrical specimens since rubber membranes are required to enclose both the inner and outer walls of the specimen.

The hollow cylinder apparatus (HCA) used in this study was recently developed at University College Dublin (UCD), Ireland (O'Kelly and Naughton, 2003 a, b; 2005). The new apparatus was designed to facilitate tests on hollow cylindrical specimens of $100 \mathrm{~mm}$ outer

\footnotetext{
${ }^{1}$ Lecturer, Department of Civil, Structural and Environmental Engineering, University of Dublin, Trinity College, Ireland, and formerly Scott Wilson Consulting Engineers, UK.

${ }^{2}$ Lecturer, School of Engineering, Institute of Technology, Sligo, Ireland.
} 
diameter, which in the case of cohesive soils could be prepared from $100 \mathrm{~mm}$ diameter piston samples with the minimum of additional disturbance. Numerical analysis (Naughton and O'Kelly, 2005) indicated that an inner specimen diameter of $71 \mathrm{~mm}$ was the most suitable in order to reduce the level of stress non-uniformity that can occur across the specimen wall thickness under generalized stress conditions to an acceptable level. A wet-pluviation preparation method was perfected for sand specimens of these dimensions and the initial properties of these specimens were studied. While wet-pluviation techniques have been used by other researchers to prepare hollow cylindrical specimens, the new apparatus had different specimens dimensions, for example Vaid et al. (1990) used specimens $152 \mathrm{~mm}$ outer diameter, $102 \mathrm{~mm}$ inner diameter and $302 \mathrm{~mm}$ high, and it was necessary to study the repeatability of the new test method and assess the significance of procedural errors on the constitutive response. The specimen preparation apparatus is described and the effects of the pluviation rate and the level of specimen densification on the repeatability and initial characteristics of the sand specimens quantified.

\section{Overview of the UCD HCA}

The apparatus subjects a hollow cylindrical specimen, $50.0 \mathrm{~mm}$ outer radius, $35.5 \mathrm{~mm}$ inner radius and nominally $200 \mathrm{~mm}$ high, to a system of axial (W) and torsional (T) loads, and independently controlled confining pressures $\left(\mathrm{p}_{\mathrm{o}}\right.$ and $\left.\mathrm{p}_{\mathrm{i}}\right)$ that are applied to the outer cell chamber and the inner bore cavity of the specimen (Fig. 1). The deformational response of the specimen was recorded using local instrumentation, comprising three inclinometer gages and two proximity transducers, and external instrumentation that recorded the displacement and rotation of the loading piston and measures changes in the volumes of the inner bore cavity and the specimen itself. The pressure cell had an internal reaction cage outside of which an acrylic cylinder was fitted to seal the outer cell chamber. The apparatus was computer-controlled to regulate the stresses $\left(\sigma_{\mathrm{z}}, \sigma_{\mathrm{r}}, \sigma_{\theta}, \tau_{\mathrm{z} \theta}\right)$ induced in the specimen (Fig. $1 \mathrm{~b}$ ) to $0.5 \mathrm{kPa}$, and the strain response was recorded to better than $5 \times 10^{-3}$ and $6 \times 10^{-5} \%$, using the internal and external instrumentation, respectively. The stresses $\left(\sigma_{\mathrm{z}}, \sigma_{\mathrm{r}}, \sigma_{\theta}, \tau_{\mathrm{z} \theta}\right)$ and strains $\left(\varepsilon_{\mathrm{z}}, \varepsilon_{\mathrm{r}}, \varepsilon_{\theta}, \gamma_{\mathrm{z} \theta}\right)$ were resolved to determine the magnitudes and orientations of the principal stresses and strains (Fig. 1c) using the Mohr-Circle of Stress analysis. The magnitudes of the three principal stresses and the orientation $\left(\alpha_{\sigma}\right)$, of the major-minor principal stress axes to the vertical direction, were independently controlled in this manner.

(a)

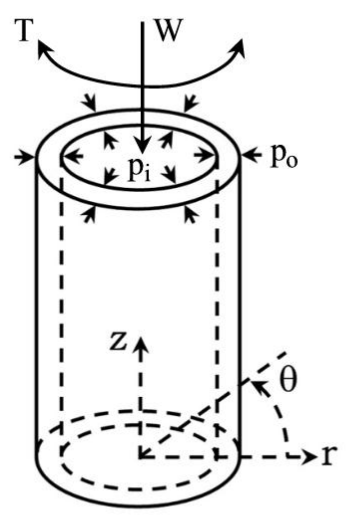

(b)

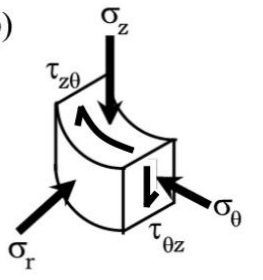

(c)

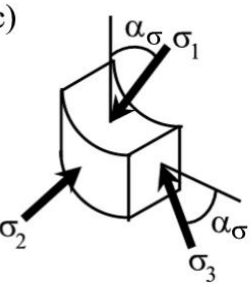

(a) Applied loads and pressures. (b) Induced normal and shear stresses. (c) Principal stresses. FIG. 1-Systems of loads, pressures and stresses for hollow cylindrical specimens 


\section{Overview of the specimen preparation method}

Hollow cylindrical specimens having identical dimensions and perfectly concentric with the loading axis were formed in the new HCA using a wet pluviation and tapping technique. The specimen preparation apparatus, shown assembled on the specimen base pedestal in Fig. 2, comprised a three-split inner mould, a two-split outer mould, a specimen extension collar and an annular overflow container. The preparation method involved depositing saturated sand into the annular void formed by the two moulds that were both lined beforehand with rubber membranes. The sand, of known dry solid mass, was deposited from a flask fitted with a glass tube nozzle. The height through which the sand grains were allowed to fall was such that the grains gently rained downwards on an individual basis until an excess of sand, over that required, had been deposited.

\section{Assembly of the specimen preparation apparatus}

The lower end of the inner mould was fitted in the top of the base pedestal in a tapered groove that ensured that the assembled mould was fully expanded to consistently produce an inner specimen radius of $35.5 \mathrm{~mm}$, perfectly concentric with the loading axis, and also allowed for the mould to collapse inward for disassembly later. The two halves of the outer mould were mated, with correct alignment provided by four tapered pins, and clamped around the bottom loading platen. Separate inner and outer specimen membranes lined the faces of the moulds. Two o-rings compressed between the outer mould and the bottom loading platen sealed the bottom end of the specimen. A suction of about $10 \mathrm{kPa}$ was applied via a geotextile that lined the inner surface of the outer mould in order to hold the membrane taut over the full height of the specimen. A 1.7-liter annular container was fitted around the outer mould. An extension collar sealed against the top of the outer mould. The collar and the inner mould allowed the pluviation of an annular column of sand slightly greater than the required initial specimen height of 200 $\mathrm{mm}$.

The annular cavity formed by the two moulds was flooded with water up to the overflow level on the extension collar. With the nozzle tip submerged, the sand flask was inverted and slowly moved around the top of the annular cavity such that the sand was uniformly deposited. The excess water exited via the overflow pipe on the extension collar and was collected in the annular container. The distance between the top of the outer mould and the overflow pipe was such that the individual sand grains had reached their terminal velocities before settling to the top of the outer mould.

Pluviation was continued until an excess of sand over that required to form the $200 \mathrm{~mm}$ high specimen had been deposited. The extension collar was transparent so that the pluviation rate and the final specimen height that had been deposited could be observed. Then the extension collar was removed and the top of the specimen was carefully trimmed back until it was level with the top of the outer mould to reduce the specimen height to $200 \mathrm{~mm}$. The excess sand retained in the annular container and remaining in the sand flask was collected, oven dried and weighed, allowing calculation of the dry mass of sand in the specimen. Although great care was taken in forming the test specimens used in this study, approximately 10 to $15 \mathrm{~g}$ of sand was invariably mislaid during specimen preparation. 


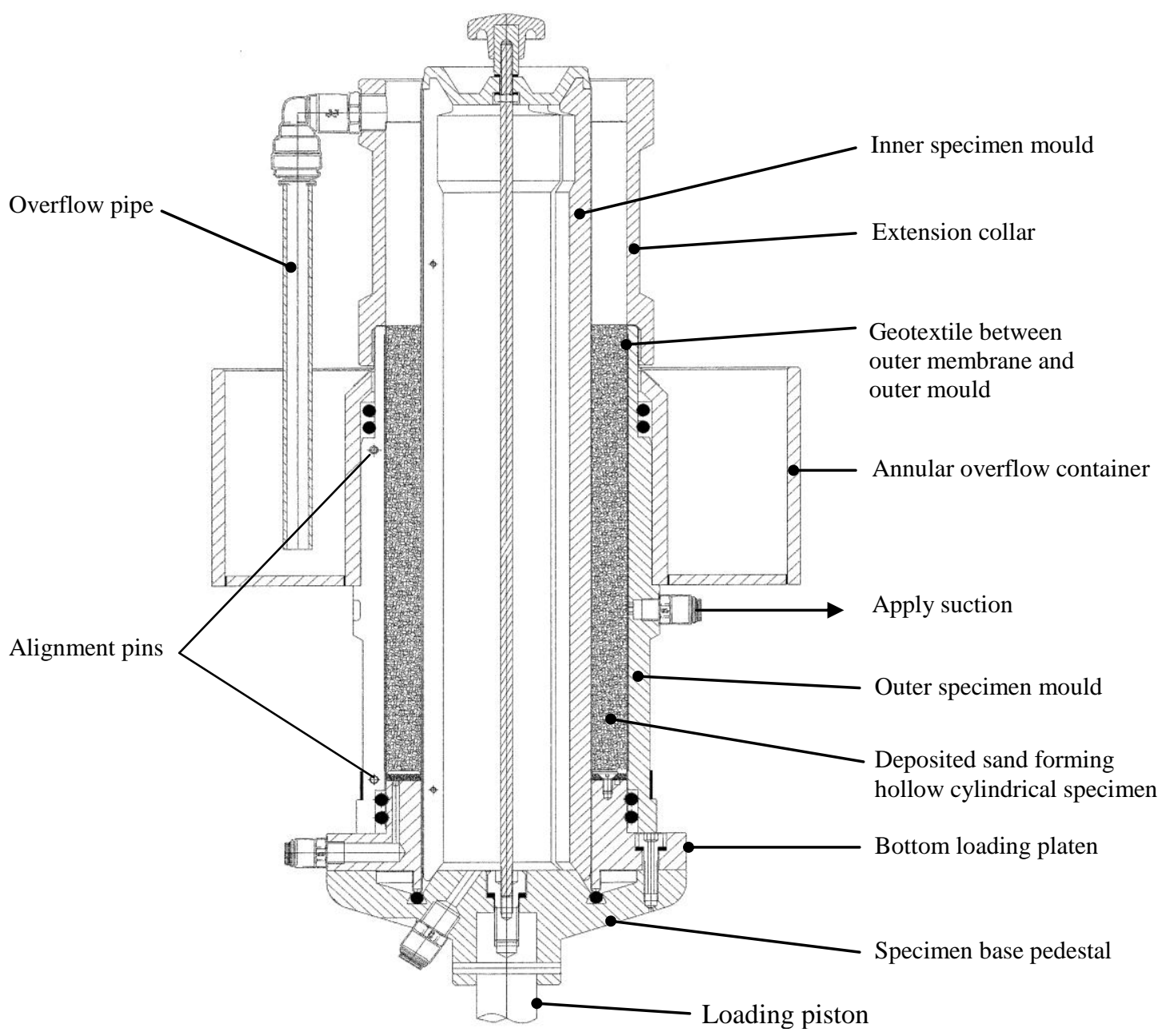

FIG. 2-The specimen preparation apparatus

The top loading platen was placed on top of the specimen, acting as a temporary surcharge load, after the annular container had been removed. The top platen had been precision machined during manufacture so that it could just slide down along the lightly dusted inner specimen membrane and into the annular cavity formed by the two moulds. The top platen was designed to accommodate strains of up to $20 \%$ during densification of the specimen without a loss of contact occurring between the top platen and the top of the specimen. A head of water corresponding to the elevation of the top platen was applied to the specimen via the open drainage ports on the top and bottom platens.

Densification was achieved by uniformly tapping around the outer mould using a wooden mallet. The $2.4 \mathrm{kPa}$ surcharge provided by the self-weight of the top loading platen produced a specimen of uniform density (Vaid et al. 1990). The reduction in the specimen height was monitored during densification by recording to $0.01 \mathrm{~mm}$ the downward movement of the top loading platen using a dial gauge. The inner mould maintained the correct alignment of the top loading platen as it settled with the top of the specimen. Densification was continued until the 
specimen height had been reduced to the target value calculated for the chosen initial void ratio. Trial tests indicated that very loose, wet-pluviated specimens of uniform sand could be readily compacted to about $95 \%$ relative density. Further densification could have been achieved but the energy imparted to the specimen was considered excessive and would have most likely resulted in non-uniform compaction of the sand.

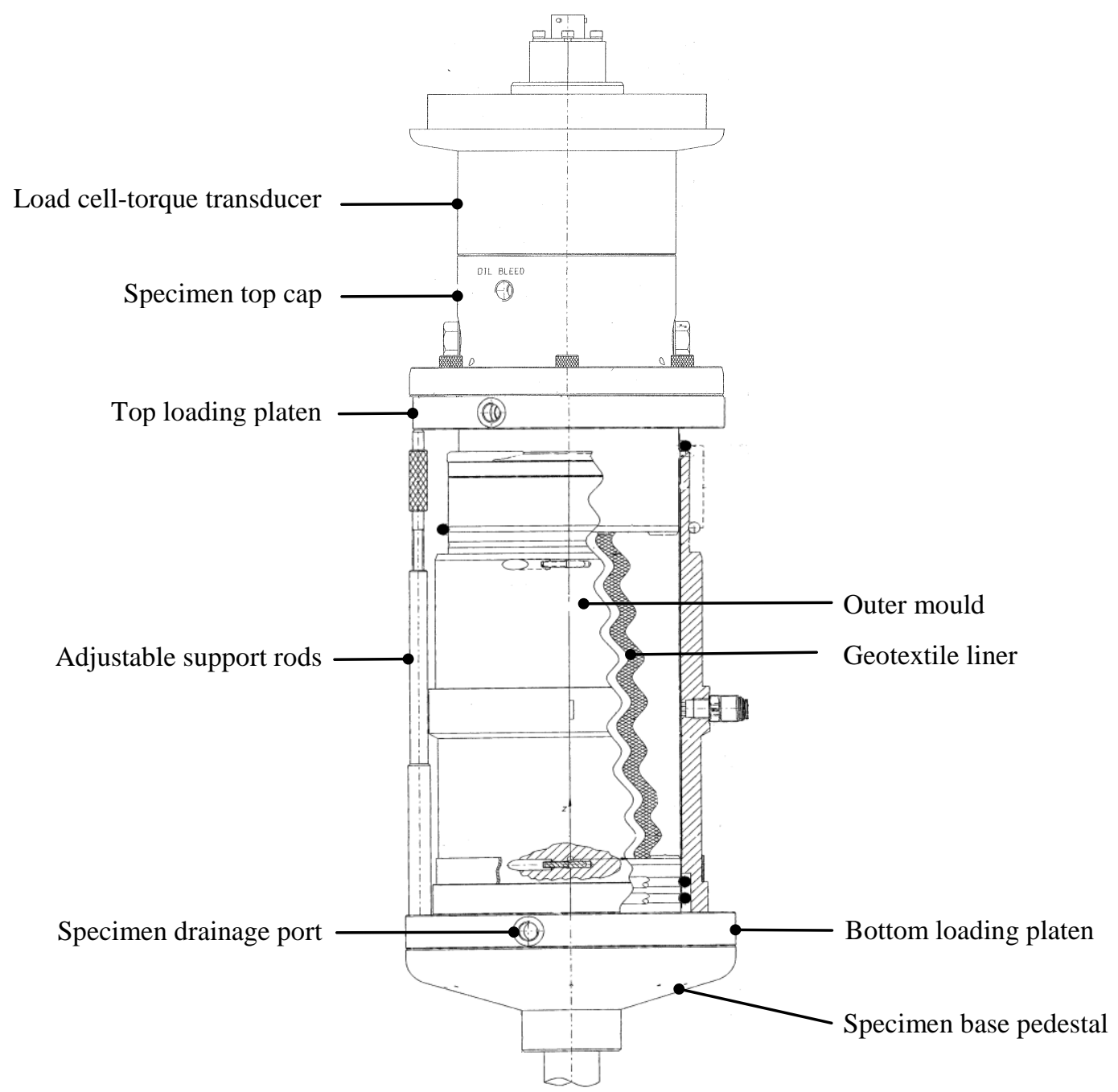

FIG. 3-Sealing the inner bore cavity of the specimen

Water was permeated up through the specimen under a $100 \mathrm{~mm}$ head of water over a period of about half an hour to ensure that any air that had become lodged between the specimen membranes and the top loading platen was removed. The specimen was then fully enclosed by sealing the inner and outer membranes against the top loading platen using two o-rings. A suction of $30 \mathrm{kPa}$ was applied to the specimen via the drainage ports, which made the specimen self-supporting. The moulds were carefully dismantled and removed. The initial dimensions of the specimen were recorded and the instrumentation inside the inner bore cavity was fitted. Three adjustable spacing rods were fitted between the top and bottom loading platens to minimize specimen disturbance that may otherwise have occurred in connecting the top loading 
platen to the specimen top cap (Fig. 3). The inner bore cavity of the specimen was sealed when this connection was secured. The remaining instrumentation was fitted to the outer specimen wall and the final assembly of the HCA pressure cell was completed. The outer cell chamber and the inner bore cavity were simultaneously flooded with water and pressured to $10 \mathrm{kPa}$. The suction was removed and equal confining pressures of $50 \mathrm{kPa}$ were applied to the specimen under undrained conditions. This was sufficient to raise the pore water pressure in the specimen to about $10 \mathrm{kPa}$.

\section{Specimen saturation}

Full saturation of the sand was achieved by isotropically loading the specimen to $150 \mathrm{kPa}$ from the $50 \mathrm{kPa}$ achieved at the end of the specimen preparation stage. The specimen was allowed to stabilize overnight and the applied specimen back- pressure was continuously adjusted to maintain a mean effective confining stress $\sigma_{\mathrm{m}}$ ', of $50 \mathrm{kPa}$. The value of the pore pressure parameter B (Skempton 1954) was measured by isotropically loading the specimen using increments of the mean confining stress applied under undrained conditions. The specimen was considered saturated for practical purposes with $\mathrm{B}>0.98$.

\section{Measurement of initial specimen dimensions}

The development of the specimen preparation apparatus included an analysis of the tolerances on the radial specimen dimensions using a computer-aided design package, which indicated that inner and outer specimen radii of $35.47 \pm 0.07$ and $49.98 \pm 0.16 \mathrm{~mm}$, and a specimen wall thickness of $14.51 \pm 0.23 \mathrm{~mm}$, were produced. These dimensions do not include the thickness of the enclosing membranes. The actual dimensions of the specimen were measured in practice for greater accuracy. The outer specimen radius was measured to $0.1 \mathrm{~mm}$ using $\pi$ tape. The inner specimen radius was calculated to $0.1 \mathrm{~mm}$ from the depth of water recorded after filling the inner bore cavity of the specimen with a known volume of water. The specimen height was measured to $0.01 \mathrm{~mm}$ using a vernier caliper. The configuration of the specimen moulds ensured that the inner and outer specimen walls were perfectly circular and concentric with the loading axis.

\section{Properties of test sand}

Hollow cylinder testing was conducted on specimens of white Leighton Buzzard sand (Table 1), a uniform, medium sand with sub-angular grains, formed using the specimen preparation method described above.

TABLE 1-Some physical properties of Leighton Buzzard sand.

\begin{tabular}{lc}
\hline Property & Value \\
\hline Coefficient of uniformity, $\mathrm{C}_{\mathrm{U}}$ & 1.32 \\
Coefficient of curvature, $\mathrm{C}_{\mathrm{C}}$ & 0.96 \\
$\mathrm{D}_{10}(\mathrm{~mm})$ & 0.44 \\
Specific gravity of solids & 2.64 \\
Maximum void ratio & $0.80 \pm 0.03$ \\
Minimum void ratio & $0.53 \pm 0.01$ \\
\hline
\end{tabular}




\section{Effect of pluviation rate on initial properties}

The effect of the pluviation rate on the initial properties of the specimen was studied. The pluviation rate was controlled by fitting nozzles of different bore diameters to the sand flask. Test specimens of Leighton Buzzard sand, $50.0 \mathrm{~mm}$ outer radius, $35.5 \mathrm{~mm}$ inner radius and 200 $\mathrm{mm}$ high, were formed using depositing nozzles of 4.2, 8.0 and $10.9 \mathrm{~mm}$ bore diameters. The $10.9 \mathrm{~mm}$ nozzle had an outer diameter of $12.6 \mathrm{~mm}$ and was the largest nozzle that could have been comfortably moved around the annulus between the assembled specimen preparation moulds. However, it proved difficult to kept the 12.6-mm nozzle tip submerged while at the same time inverting the sand flask. Moreover, air locks regularly formed along the nozzle length and caused the deposition of sand to be uneven. This problem did not arise when the smaller bore nozzles were used although the pluviation rate was much slower, for example the period required to pluviate a specimen using the $4.2 \mathrm{~mm}$ diameter nozzle was six times that for the $10.9 \mathrm{~mm}$ nozzle. Only one specimen was formed using the $4.2 \mathrm{~mm}$ nozzle due to the significant time of 180 minutes required. The largest variation measured in the dry densities of the specimens (Table 2) was within $3 \%$ of the mean values. While no significant differences were found to occur in the dry densities for the 8.0 and $10.9 \mathrm{~mm}$ nozzles, the former produced slightly less variability in the dry mass of sand that was deposited and also produced a slightly higher initial void ratio.

TABLE 2-Dry densities and void ratios of specimens formed using different nozzle diameters

\begin{tabular}{cccccc}
\hline $\begin{array}{c}\text { Nozzle bore } \\
\text { diameter } \\
(\mathrm{mm})\end{array}$ & $\begin{array}{c}\text { Number of } \\
\text { specimens }\end{array}$ & $\begin{array}{c}\text { Time to deposit } \\
\text { sand } \\
(\mathrm{min})\end{array}$ & $\begin{array}{c}\text { Mean dry } \\
\text { mass } \\
(\mathrm{g})\end{array}$ & $\begin{array}{c}\text { Mean dry } \\
\text { density } \\
\left(\mathrm{Mg} / \mathrm{m}^{3}\right)\end{array}$ & $\begin{array}{c}\text { Mean void } \\
\text { ratio }\end{array}$ \\
\hline 10.9 & 10 & 30 & $1177 \pm 14$ & $1.51 \pm 0.02$ & $0.75 \pm 0.02$ \\
8.0 & 12 & 40 & $1164 \pm 11$ & $1.50 \pm 0.01$ & $0.77 \pm 0.02$ \\
4.2 & 1 & 180 & 1180 & 1.52 & 0.74 \\
\hline
\end{tabular}

\section{Analysis of error in the void ratio}

The actual void ratios of the Leighton Buzzard sand specimens were found to have been within $2.6 \%$ of the targeted values. However, this variation was significantly larger than the 0.6 $\%$ variation in the void ratio of Ottawa sand specimens prepared using a similar technique and tested in the University of British Colombia (UBC) HCA (Vaid and Negussey, 1988). The UBC specimens were $51.0 \mathrm{~mm}$ inner radius, $76.0 \mathrm{~mm}$ outer radius, and $302 \mathrm{~mm}$ high.

The larger error in the initial void ratio for the UCD specimens may be explained in part by the difference in the specimen volumes, with the volume of the UBC specimens about 3.8 times that of the UCD specimens. The errors in the void ratios for the UCD and UBC specimens were also quantified by developing the method proposed by Vaid and Sivathayalan (1996), which was originally used to determine errors for solid cylindrical specimens (Appendix A). The overall error in the initial void ratio was calculated as the sum of the errors calculated separately for the inner circumference, wall thickness, height and dry mass of sand in the specimen. The analysis assumed that the error in the dry solid masses of the UBC specimens was the same as the error of $10 \mathrm{~g}$ recorded for the UCD specimens. This was not a weighing error but an estimate of the dry 
mass of sand that was mislaid during specimen preparation. The dry solid masses of the UBC specimens were calculated from the known specimen volume, assuming a specific gravity of 2.65 for Ottawa sand (Table 3).

TABLE 3-Some physical properties and measurement errors for hollow cylindrical specimens

\begin{tabular}{lcccc}
\hline Initial property & \multicolumn{2}{c}{ UCD HCA } & \multicolumn{2}{c}{ UBC HCA } \\
& Value & $\begin{array}{c}\text { Estimated } \\
\text { error }\end{array}$ & Value & $\begin{array}{c}\text { Estimated } \\
\text { error }\end{array}$ \\
\hline Inner radius $(\mathrm{mm})$ & 35.5 & 0.1 & 51.0 & 0.1 \\
Outer radius $(\mathrm{mm})$ & 50.0 & 0.1 & 76.0 & 0.1 \\
Wall thickness $(\mathrm{mm})$ & 14.5 & 0.1 & 25.0 & 0.1 \\
Height $(\mathrm{mm})$ & 200 & 0.01 & 300 & 0.01 \\
Volume $\left(\mathrm{cm}^{3}\right)$ & 779 & - & 2992 & - \\
Dry mass of sand $(\mathrm{g})$ & 1170 & 10 & 4483 & 10 \\
\hline
\end{tabular}

The analysis, summarized in Table 4, indicated that the overall error in the initial void ratio for the UCD specimens was about 2.5 times that for the UBC specimens, and was consistent with the ratio of the corresponding specimen volumes. The larger wall thickness and dry masses of sand in the UBC specimens caused a lower overall error in the void ratio. In general, the larger the specimen volume, the larger the dry mass of sand, and hence the lower the error in the measured initial void ratio.

TABLE 4-Summary of errors in the void ratios for hollow cylindrical specimens

\begin{tabular}{lccc}
\hline \multirow{2}{*}{ Error component } & \multicolumn{2}{c}{ Magnitude } \\
\hline Inner circumference & $\frac{\Delta c}{c}$ & $2.2 \times 10^{-4}$ & UBC HCA \\
Wall thickness & $\frac{\Delta t}{t}$ & $68.9 \times 10^{-4}$ & $40.0 \times 10^{-4}$ \\
Height & $\frac{\Delta H}{H}$ & $0.5 \times 10^{-4}$ & $0.3 \times 10^{-4}$ \\
Dry mass of sand & $\frac{\Delta m_{s}}{m_{s}}$ & $85.5 \times 10^{-4}$ & $22.3 \times 10^{-4}$ \\
Combined error & & $157.1 \times 10^{-4}$ & $64.1 \times 10^{-4}$ \\
\hline
\end{tabular}

\section{Repeatability of specimen preparation method}

The repeatability of the specimen preparation method was studied by comparing the stressstrain responses of three identically prepared sand specimens that had been isotropically consolidated from a mean effective stress of 50 to $200 \mathrm{kPa}$. The dense specimens of Leighton Buzzard sand (denoted Test I, II and III) were prepared to achieve a target initial void ratio of 0.60 (relative density of $75 \%$ ) and the actual void ratios were measured in the range $0.58-0.61$ 
(Table 5). The confining pressures applied to the outer cell chamber and the inner bore cavity of the specimen were simultaneously increased under a constant back pressure, while the axial and torsional loads were maintained equal to zero. The deformational responses of the specimens were recorded by the local instrumentation. The responses, plotted in terms of the mean effective confining stress versus the principal $\left(\varepsilon_{1}, \varepsilon_{2}, \varepsilon_{3}\right)$ and volumetric $\left(\varepsilon_{\mathrm{vol}}\right)$ strains (Fig. 4), were largely linear and displayed reasonable agreement. The response of Test III deviated slightly, nevertheless, the volumetric strain response (Fig. 4d) remained within $5 \%$ of that recorded for Tests I and II. Some scatter was evident in the $\varepsilon_{1}$ response, which corresponded to the axial strain $\left(\varepsilon_{\mathrm{z}}\right)$ response under isotropic consolidation. The data indicate that the constitutive responses of the specimens were not significantly influenced by the $2.6 \%$ variation in the initial void ratios of the specimens.

TABLE 5-Isotropic consolidation tests on identically prepared UCD specimens

\begin{tabular}{lccc}
\hline Initial properties & \multicolumn{3}{c}{ Test designation } \\
& I & II & III \\
\hline Dry mass $(\mathrm{g})$ & 1164 & 1180 & 1160 \\
Dry density $\left(\mathrm{Mg} / \mathrm{m}^{3}\right)$ & 1.65 & 1.67 & 1.64 \\
Void ratio & 0.60 & 0.58 & 0.61 \\
Height $(\mathrm{mm})$ & 181.5 & 181.4 & 181.5 \\
Inner radius $(\mathrm{mm})$ & 35.5 & 35.5 & 35.5 \\
Outer radius $(\mathrm{mm})$ & 50.0 & 50.0 & 50.0 \\
\hline
\end{tabular}

\section{Inherent anisotropy of sand specimens}

The level of inherent anisotropy arising due to densification during preparation of specimens was also studied. Four Leighton Buzzard sand specimens were formed at different initial void ratios (Table 6) in the HCA using the refined preparation method. The specimens were isotropically consolidated from $\sigma_{\mathrm{m}}{ }^{\prime}=100$ to $200 \mathrm{kPa}$ and the deformational responses of the specimens were recorded using the local instrumentation. The inherent anisotropy of the specimens was studied by comparing the principal strain responses (Fig. 5). Identical principal strain responses would have been observed if the specimen were isotropic (indicated by solid lines in Fig. 5). Under the isotropic consolidations conditions described, the axial strain $\left(\varepsilon_{\mathrm{z}}\right)$ response corresponded to the major principal strain $\left(\varepsilon_{1}\right)$, and the radial $\left(\varepsilon_{\mathrm{r}}\right)$ and circumferential $\left(\varepsilon_{\theta}\right)$ strain responses corresponded to the intermediate $\left(\varepsilon_{2}\right)$ and minor $\left(\varepsilon_{3}\right)$ principal strains. The specimens were found to have had a higher level of deformability in the radial $\left(\varepsilon_{2}\right)$ direction than in the axial or circumferential $\left(\varepsilon_{1}\right.$ and $\left.\varepsilon_{3}\right)$ directions. For comparative purposes, least squares best-fit lines were fitted to the data in Fig. 5, with the strain gradients listed in Table 7 calculated from the slopes of the best-fit lines. 


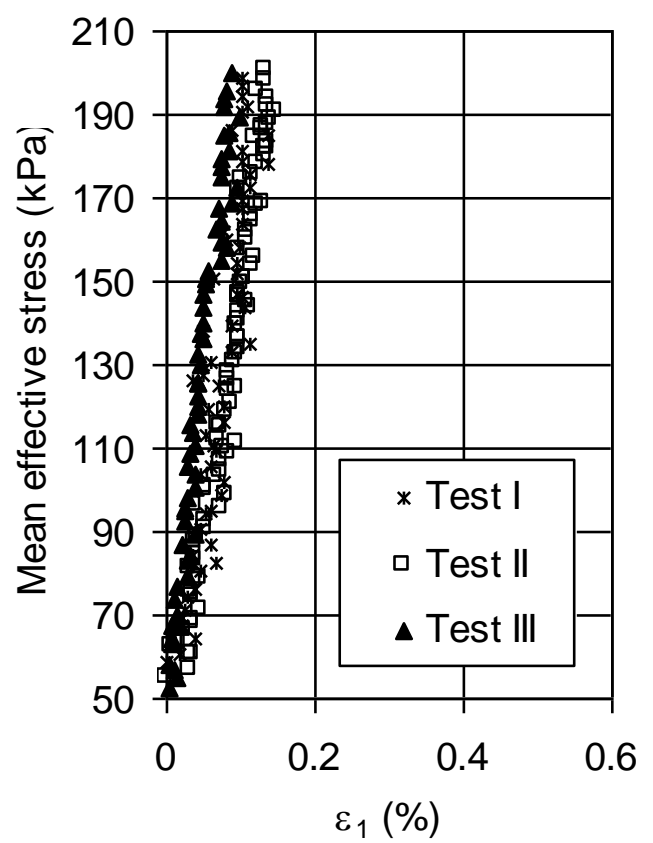

(a)

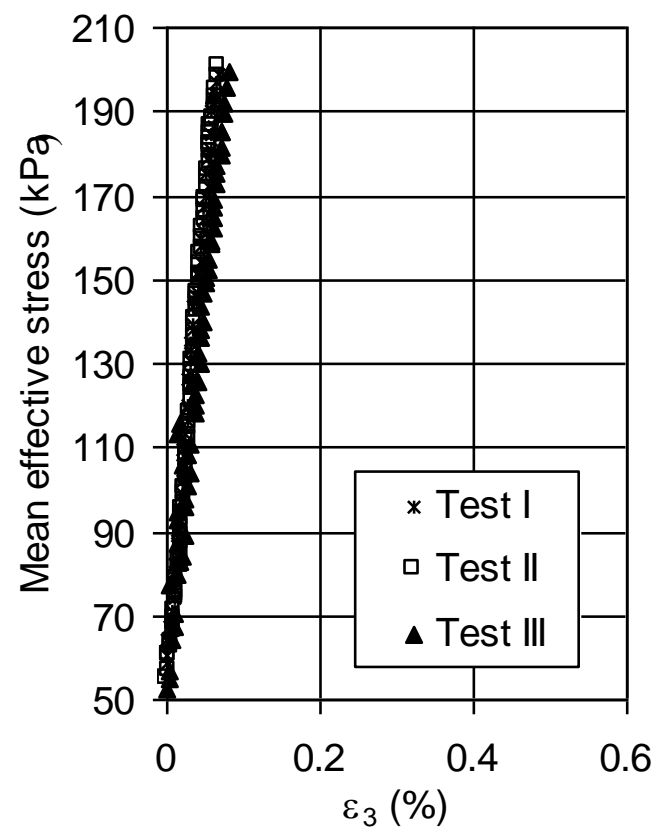

(c)

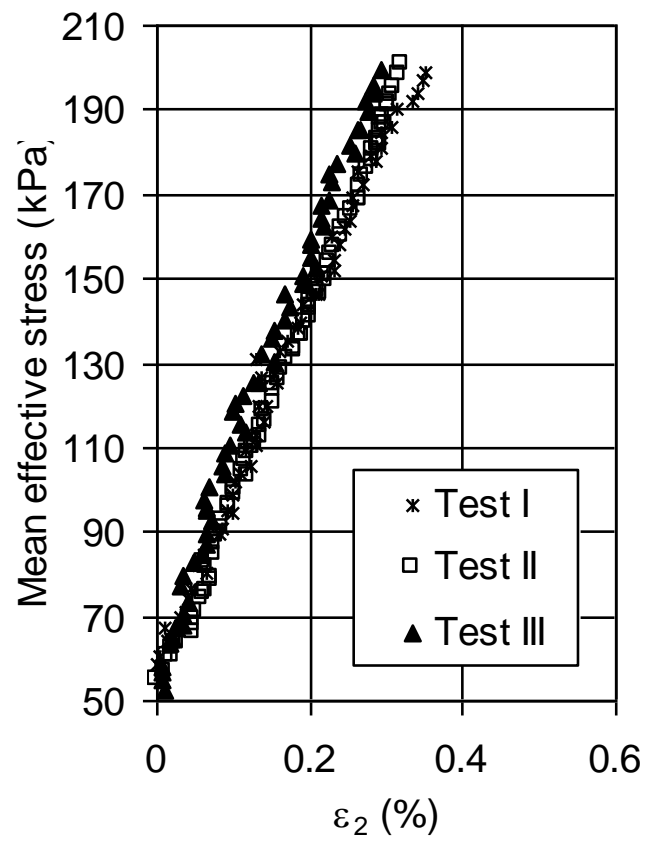

(b)

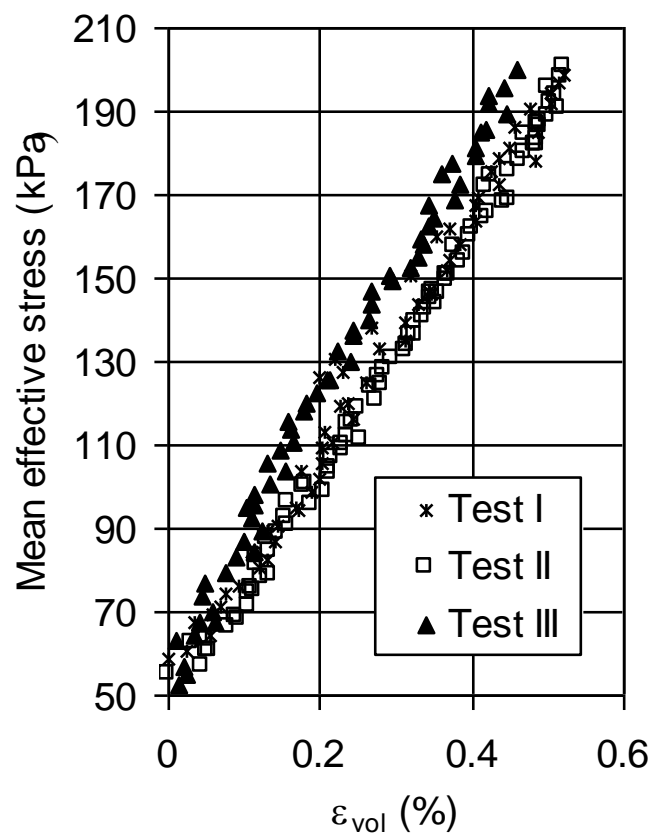

(d)

FIG. 4-(a) $\varepsilon_{1}$, (b) $\varepsilon_{2}$, (c) $\varepsilon_{3}$ and (d) $\varepsilon_{\mathrm{vol}}$, versus $\sigma_{\mathrm{m}}$ '

The strain gradients listed in Table 7 indicate that the specimens were strongly cross anisotropic in the horizontal $\varepsilon_{2}-\varepsilon_{3}$ plane, with the $\varepsilon_{2}-\varepsilon_{3}$ strain gradients about an order of magnitude greater than those in the vertical $\varepsilon_{1}-\varepsilon_{3}$ and $\varepsilon_{1}-\varepsilon_{2}$ planes. This trend was attributed to the specimen preparation method, where densification by tapping appeared to have a far greater 
effect on the specimen properties in the axial direction than in the horizontal directions. This is supported by the fact that the $\varepsilon_{2}-\varepsilon_{3}$ response of Test IH13, which did not undergo any densification during specimen preparation, was broadly similar to that recorded for Tests IH45 and IH76 (Fig. 5c). Further examination of the $\varepsilon_{1}-\varepsilon_{3}$ and $\varepsilon_{1}-\varepsilon_{2}$ responses (Fig. 5 (a) and (b)), suggests that the level of inherent anisotropy decreased at higher levels of densification (decreasing void ratio), and is consistent with experimental observations on Ottawa sand reported by Vaid and Sayao (1995).

TABLE 6-Isotropic consolidation tests on anisotropic specimens

\begin{tabular}{lcccc}
\hline Initial property & \multicolumn{3}{c}{ Test designation } \\
& $\mathrm{IH} 13$ & $\mathrm{IH} 45$ & $\mathrm{IH72}$ & $\mathrm{IH76}$ \\
\hline Dry mass $(\mathrm{g})$ & 1160 & 1155 & 1162 & 1168 \\
Dry density $\left(\mathrm{Mg} / \mathrm{m}^{3}\right)$ & 1.49 & 1.57 & 1.64 & 1.66 \\
Void ratio & 0.77 & 0.68 & 0.61 & 0.59 \\
Height $(\mathrm{mm})$ & 200.0 & 192.1 & 181.4 & 181.5 \\
Inner radius $(\mathrm{mm})$ & 35.5 & 35.5 & 35.5 & 35.5 \\
Outer radius $(\mathrm{mm})$ & 50.0 & 50.0 & 50.0 & 50.0 \\
\hline
\end{tabular}

TABLE 7-Strain gradients from isotropic consolidation tests

\begin{tabular}{lcccccc}
\hline $\begin{array}{l}\text { Test } \\
\text { designation }\end{array}$ & \multicolumn{2}{c}{ Strain component relationships } \\
& Gradient & $\varepsilon_{1}-\varepsilon_{2}$ & \multicolumn{2}{c}{$\varepsilon_{1}-\varepsilon_{3}$} & $\varepsilon_{2}-\varepsilon_{3}$ \\
& 0.051 & 99.2 & 0.157 & 99.5 & 3.077 & 99.2 \\
IH13 & 0.077 & 95.4 & 0.203 & 97.9 & 2.181 & 96.1 \\
IH45* & 0.124 & 99.1 & 0.557 & 94.4 & 4.486 & 92.7 \\
IH72 & 0.096 & 99.8 & 0.694 & 98.23 & 2.886 & 98.6 \\
IH76 & & & Gradient & $\mathrm{R}^{2}(\%)$ & Gradient & $\mathrm{R}^{2}(\%)$ \\
\hline
\end{tabular}

* Based on linear portion of the data up to $\sigma_{\mathrm{m}}{ }^{\prime}=160 \mathrm{kPa}$

\section{Correction for membrane penetration effects}

The penetration of the rubber membranes into the voids between the sand grains adjoining the specimen walls is dependent on the effective confining stress applied. Consequently, a systematic error occurs in the recorded volume change of the specimen during drained tests, or the recorded pore water pressure response during undrained tests. In the case of hollow cylindrical specimens, errors occur in the inner and outer specimen radii calculated from volume changes of the specimen and its inner bore cavity recorded by the external instrumentation.

The amount of membrane penetration, and hence the magnitude of the error in the external measurements, was studied using the non-destructive, specimen specific method developed by Sivathayalan and Vaid (1998). Since the hollow cylindrical tests on the saturated sand were of relatively short duration, the amount of air that could diffuse into the specimens via the rubber membranes was small, and single rubber membranes of $0.38 \mathrm{~mm}$ thickness enclosed the inner and outer specimen walls. The amount of membrane penetration was calculated using the method 
$12 \mathrm{JJ}$

of Sivathayalan and Vaid (1998) from the specimen deformations recoded by the external instrumentation during isotropic increments and decrements of the confining stress. The data recorded using the external instrumentation during the study of inherent anisotropy described earlier was used to assess the amounts of membrane penetration for Leighton Buzzard sand specimens prepared at different initial void ratios.

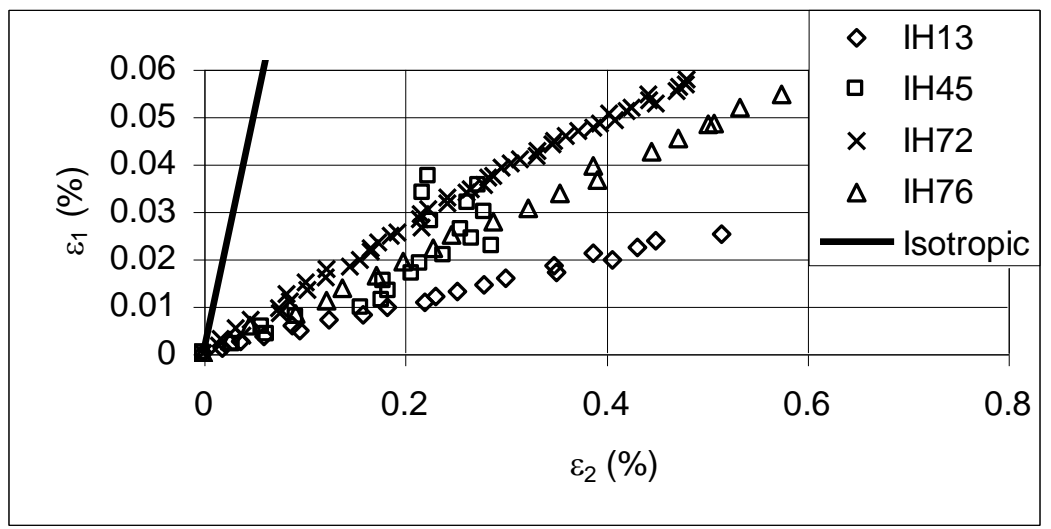

(a)

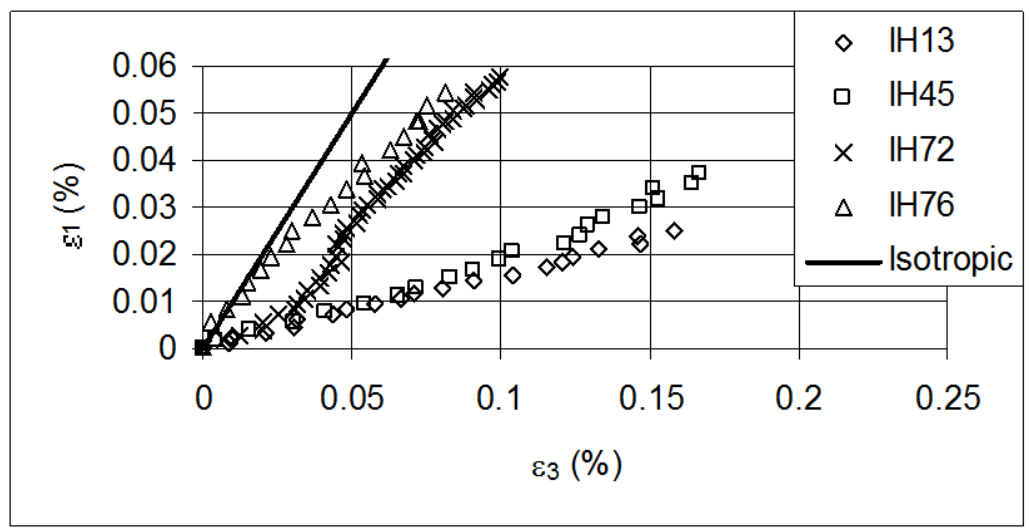

(b)

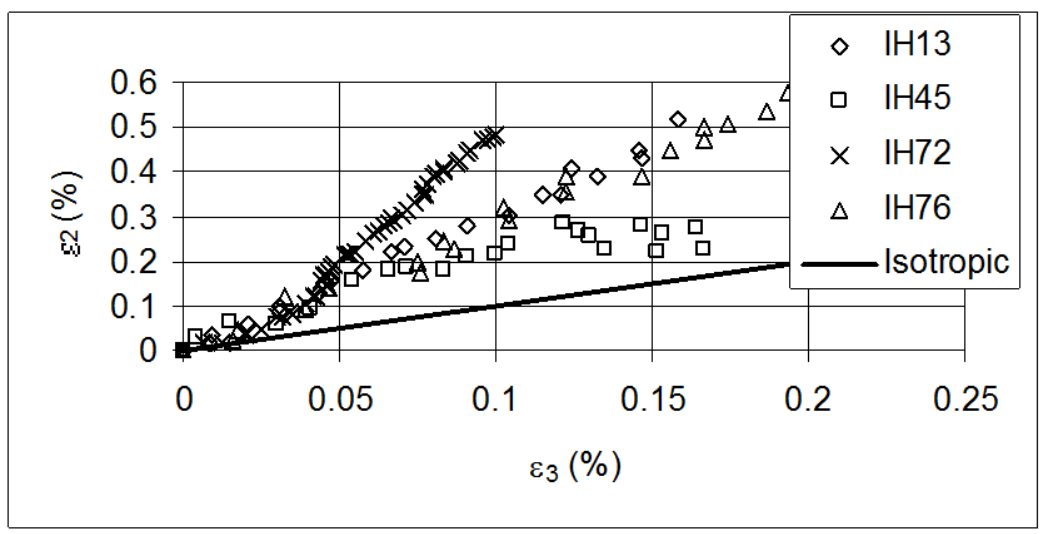

(c)

FIG. 5-Inherent anisotropy of sand specimens with different initial void ratios 
The test results shown in Fig. 6 suggest that the unit membrane penetration, defined as the apparent volume change per surface area due to membrane penetration, and the mean confining stress, in terms of both the total and effective stress conditions, are directly related. Moreover, the gradients of the unit membrane penetration versus mean confining stress plots for the different specimens were similar (Table 8), which would suggest that the level of unit membrane penetration was independent of the initial void ratios of the specimens.

Sivathayalan and Vaid (1998) and Frydman et al. (1973) produced relationships between the mean grain size and the normalized unit membrane penetration, defined as the gradient of the unit membrane penetration versus logarithm mean confining stress plot. Sivathayalan and Vaid (1998) worked in terms of effective stresses whereas Frydman et al. (1973) worked in terms of total stresses. Although the test data from this study was slightly lower than that predicted by either of these methods, the method of Sivathayalan and Vaid (1998) allowed for specimen specific membrane penetration corrections, which were applied in the apparatus control program (Table 9). The amount of membrane penetration computed during the isotropic consolidation stage of the hollow cylindrical tests was used to correct for membrane penetration effects during subsequent test stages.

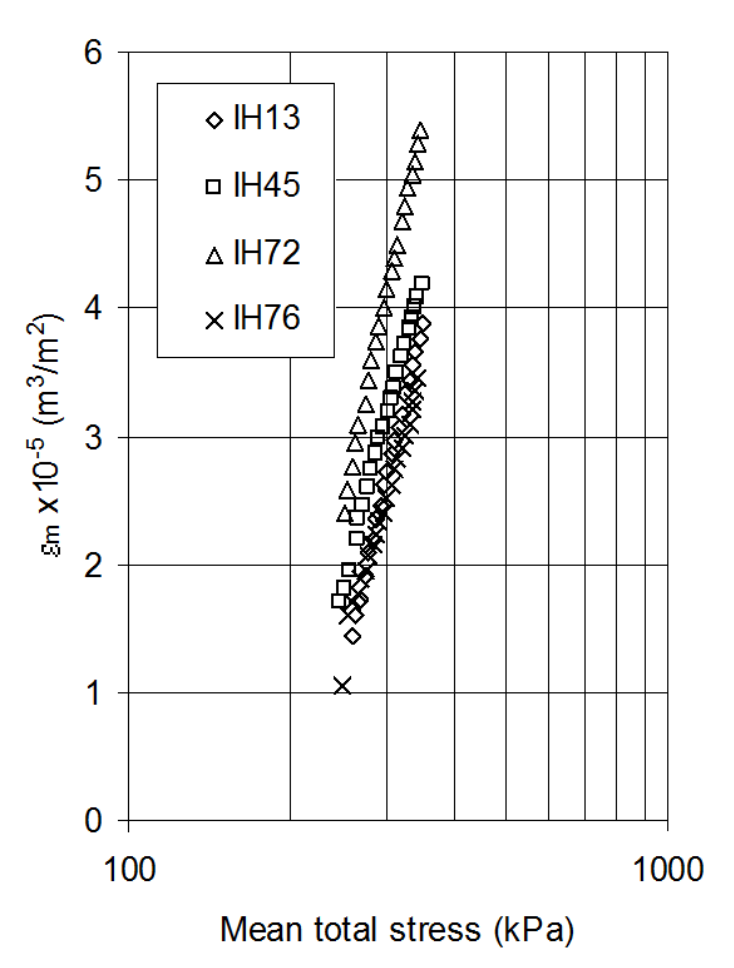

(a)

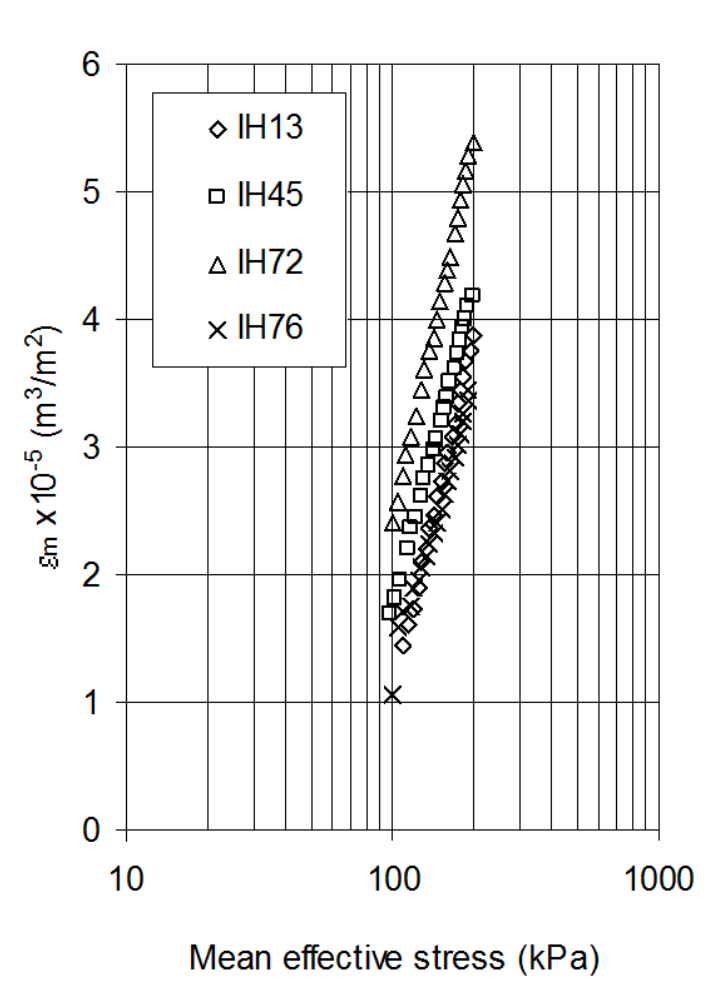

(b)

FIG. 6-Plots of unit membrane penetration versus mean confining stress

\section{Discussion}

The engineering properties of the Leighton Buzzard sand specimens formed using the refined wet-pluviation and tapping technique were assessed in a hollow cylinder apparatus. The initial 
void ratios of the fresh wet-pluviated specimens were similar and appeared to be independent of the pluviation rate, which was controlled by changing the diameter of the nozzle fitted to the sand flask that was used to deposit the specimens. The actual void ratios of the densified specimens, achieved by uniformly tapping around the outer mould, were found to vary by up to $2.6 \%$ from the targeted values. However, this variation did not appear to significantly affect the stress-strain response recorded under isotropic loading conditions. Examination of the variation in the initial void ratio using an expanded procedure originally developed for solid cylindrical specimens indicated that the error in the void ratio was inversely related to the volume of the specimen.

TABLE 8- Unit membrane penetrations normalized for different initial void ratios

\begin{tabular}{|c|c|c|}
\hline \multirow[t]{2}{*}{$\begin{array}{c}\text { Test } \\
\text { designation }\end{array}$} & \multicolumn{2}{|c|}{$\begin{array}{l}\text { Normalized unit membrane penetration } \\
\qquad\left(\mathrm{m}^{3} / \mathrm{m}^{2} / \mathrm{kPa}\right) \times 10^{-5}\end{array}$} \\
\hline & Effective stress case & Total stress case \\
\hline IH13 & 4.1 & 8.1 \\
\hline $\mathrm{IH} 45$ & 3.5 & 7.3 \\
\hline $\mathrm{IH} 72$ & 4.3 & 8.8 \\
\hline IH75 & 3.1 & 6.4 \\
\hline Mean value & 3.7 & 7.7 \\
\hline Standard deviation & 0.5 & 1.0 \\
\hline
\end{tabular}

TABLE 9-Predicted and experimental membrane penetrations

\begin{tabular}{lcc}
\hline & \multicolumn{2}{c}{$\begin{array}{c}\text { Normalized unit membrane penetration } \\
\left(\mathrm{m}^{3} / \mathrm{m}^{2} / \mathrm{kPa}\right) \times 10^{-5}\end{array}$} \\
\cline { 2 - 3 } & $\begin{array}{c}\text { Effective } \\
\text { stress case }\end{array}$ & $\begin{array}{c}\text { Total } \\
\text { stress case }\end{array}$ \\
\hline Measured in this study & 3.8 & 7.7 \\
Sivathayalan and Vaid (1998) & 6.0 & - \\
Frydman et al. (1973) & - & 8.5 \\
\hline
\end{tabular}

The wet-pluviated specimens appeared to have an inherent cross-anisotropic fabric orientated in the horizontal plane, and the initial level of anisotropy was found to have been largely independent of the initial void ratio. The inherent anisotropy of the specimens appeared to decrease at higher levels of densification. This suggests that it may be possible to produce a specific level of inherent anisotropy in the specimens by controlling the initial void ratio during preparation, although further studies are required. The experimental method for estimating the amount of membrane penetration proposed by Sivathayalan and Vaid (1998) was found to be readily programmable and a useful method for automatically correcting for membrane penetration effects during hollow cylindrical tests. 


\section{Conclusions}

Hollow cylindrical specimens of Leighton Buzzard sand prepared using a refined wet pluviation and tapping technique displayed good repeatability in terms of the initial dimensions, dry mass of sand and stress-strain responses under isotropic loading of the specimens. The error between the targeted initial void ratio and the initial void ratio actually achieved was a function of the dry mass and dimensions of the specimen. The magnitude of the error in the void ratio was found to reduce for larger initial specimen volumes. The initial void ratios of the fresh wetpluviated specimens were found to be unaffected by the pluviation rate.

The wet-pluviated specimens acquired an inherently cross-anisotropic fabric, orientated in the horizontal plane. The level of cross-anisotropy appeared to have been largely independent of the mean effective confining stress and the amount of densification achieved during specimen preparation. The specimens experienced a higher level of deformability in the radial direction than in the axial and circumferential directions under isotropic consolidation. Overall, the level of inherent anisotropy appeared to decrease at higher levels of densification (decreasing void ratio).

\section{Acknowledgements}

The research was carried out by the authors towards $\mathrm{PhD}$ degrees at University College Dublin, Ireland. The support of Tom Widdis and Eugene O'Brien is gratefully acknowledged. The first author would also like to acknowledge funding through the Pierse Newman Scholarship in Civil Engineering from University College Dublin.

\section{Reference:}

Frydman, S., Zeitlen, J.G. and Alpan, I., 1973, "The membrane effect in triaxial testing of granular soils", Journal of Testing and Evaluation, Vol. 1, No. 1, pp. 37-41.

Ishihara, K. and Yasuda, S., 1975, "Sand liquefaction under hollow cylinder torsion under irregular excitation", Soils and Foundations, Vol. 15, No. 1, pp. 45-59.

Naughton, P.J. and O'Kelly, B.C., 2005, "Stress non-uniformity in hollow cylindrical test specimens", Proceedings, ASCE/ASME/SES Conference on Mechanics and Materials, 1-3 June, Louisiana

O'Kelly, B.C. and Naughton, P.J., 2003a, "Development of the University College Dublin hollow cylinder apparatus," Proceedings, 56th Annual Canadian Geotechnical Conference, Winnipeg, 29 September-01 October, CD Rom.

O’Kelly, B.C. and Naughton, P.J., 2003b, "Development of a new hollow cylinder apparatus for generalised stress path testing," Ground Engineering, Vol. 36, No. 7, pp. 26-28.

O’Kelly, B.C. and Naughton, P.J., 2005, "Development of a new hollow cylinder apparatus for stress path measurements over a wide strain range," Geotechnical Testing Journal, Vol. 28, No. 4 (in press).

Porovic, E., 1995, "Investigations of soil behaviour using a resonant-column torsional-shear hollow cylinder apparatus", $\mathrm{PhD}$ thesis, University of London (Imperial College).

Sivathayalan, S. and Vaid, Y.P., 1998, "Truly undrained response of granular soils with no membrane penetration effects", Canadian Geotechnical Journal, Vol. 35, pp. 730-739.

Skempton, A., 1954, "The pore pressure coefficients A and B," Geotechnique, Vol. 4, pp. 143-147.

Vaid, Y.P. and Negussey, D., 1988, "Preparation of reconstituted sand specimens," Advanced triaxial 
testing of Soil and Rock, ASTM STP 977, ASTM.

Vaid, Y. P., Sayao, A., Hou, E. and Negussey, D., 1990, "Generalized stress path dependent behaviour with a new hallow cylinder torsional apparatus", Canadian Geotechnical Journal, Vol. 27, pp. 601-616.

Vaid, Y. P. and Sayao, A., 1995, "Proportional loading behaviour of sand under multiaxial stresses," Soils and Foundations, Vol. 35, No. 3, pp. 23-29.

Vaid, Y.P. and Sivathayalan, S., 1996, "Errors in estimates of void ratio of laboratory sand specimens," Canadian Geotechnical Journal, Vol. 33, pp. 1017-1020.

\section{Appendix A}

An assessment of the error in the void ratio for the hollow cylindrical sand specimens was made by developing the method originally used by Vaid and Sivathayalan (1996) to study the error for solid cylindrical specimens. The void ratio e, defined as the ratio of the volume of voids to the volume of solids, can be calculated as:

$$
e=\frac{V}{V_{S}}-1
$$

where

$\mathrm{V}=$ Specimen volume;

$\mathrm{V}_{\mathrm{s}} \quad=$ Volume of dry solids.

For a hollow cylindrical specimen of inner radius $\left(\mathrm{r}_{\mathrm{i}}\right)$, wall thickness $(\mathrm{t})$, height $(\mathrm{H})$, dry mass $\left(\mathrm{m}_{\mathrm{s}}\right)$, and specific gravity of solids $\left(\mathrm{G}_{\mathrm{s}}\right)$, the void ratio can be expressed as:

$$
\begin{aligned}
\mathrm{e} & =\frac{2 \pi \mathrm{r}_{\mathrm{i}} \mathrm{tHG}_{\mathrm{s}}}{\mathrm{m}_{\mathrm{s}}}-1 \\
& =\frac{\mathrm{ctHG} \mathrm{H}_{\mathrm{s}}}{\mathrm{m}_{\mathrm{s}}}-1
\end{aligned}
$$

where

c $\quad=$ Circumference of inner specimen wall.

Differentiating Eq. 3 gives:

$$
\mathrm{de}=\left(1+\mathrm{e}^{\prime}\right)\left(\frac{\mathrm{dc}}{\mathrm{c}}+\frac{\mathrm{dt}}{\mathrm{t}}+\frac{\mathrm{dH}}{\mathrm{H}}+\frac{\mathrm{dG}_{\mathrm{s}}}{\rho_{\mathrm{s}}}-\frac{\mathrm{dm}_{\mathrm{s}}}{\mathrm{m}_{\mathrm{s}}}\right)
$$

where

$e^{\prime} \quad=$ the true void ratio measured for infinite resolution and without error.

The maximum error in the void ratio $\Delta \mathrm{e}$, was determined as the sum of the absolute errors corresponding to the different terms in Eq. 4: 


$$
\Delta \mathrm{e}=\left(1+\mathrm{e}^{\prime}\right)\left(\frac{\Delta \mathrm{c}}{\mathrm{c}}+\frac{\Delta \mathrm{t}}{\mathrm{t}}+\frac{\Delta \mathrm{H}}{\mathrm{H}}-\frac{\Delta \mathrm{m}_{\mathrm{s}}}{\mathrm{m}_{\mathrm{s}}}\right)
$$

It can be assumed that $\Delta \mathrm{G}_{\mathrm{s}}=0$ for a test program conducted on one specific sand type. 